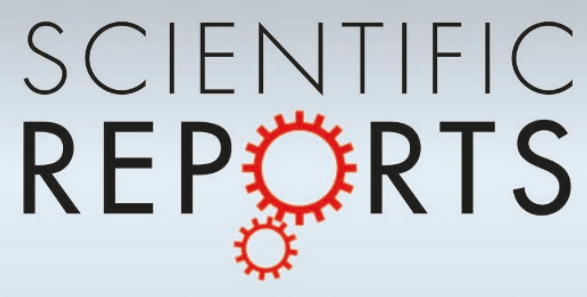

OPEN

SUBJECT AREAS:

METEORITICS

ASTEROIDS, COMETS AND

KUIPER BELT

Received

27 June 2014

Accepted

25 September 2014

Published

23 October 2014

Correspondence and requests for materials should be addressed to J.O. (ormoj@cab.intacsic.es)

\section{First known Terrestrial Impact of a Binary Asteroid from a Main Belt Breakup Event}

\author{
Jens Ormö' , Erik Sturkell ${ }^{2}$, Carl Alwmark ${ }^{3}$ \& Jay Melosh ${ }^{4}$
}

${ }^{1}$ Centro de Astrobiología (INTA-CSIC), Instituto Nacional de Técnica Aeroespacial, Ctra de Torrejón a Ajalvir, km 4, 28850 Torrejón de Ardoz, Madrid, Spain, ${ }^{2}$ Department of Earth Sciences, University of Gothenburg, Guldhedsgatan 5 A, 40530 Gothenburg, Sweden, ${ }^{3}$ Dept. of Earth and Ecosystem Sciences, Division of Geology, Lund University, Sölvegatan 12, 22362 Lund, Sweden, ${ }^{4}$ Earth, Atmospheric, and Planetary Sciences Department, 550 Stadium Mall Drive, Purdue University, West Lafayette, IN 47907-2051, USA.

Approximately 470 million years ago one of the largest cosmic catastrophes occurred in our solar system since the accretion of the planets. A 200-km large asteroid was disrupted by a collision in the Main Asteroid Belt, which spawned fragments into Earth crossing orbits. This had tremendous consequences for the meteorite production and cratering rate during several millions of years following the event. The $7.5-\mathrm{km}$ wide Lockne crater, central Sweden, is known to be a member of this family. We here provide evidence that Lockne and its nearby companion, the $0.7-\mathrm{km}$ diameter, contemporaneous, Målingen crater, formed by the impact of a binary, presumably 'rubble pile' asteroid. This newly discovered crater doublet provides a unique reference for impacts by combined, and poorly consolidated projectiles, as well as for the development of binary asteroids.

$\mathrm{T}$ he Middle Ordovician breakup event ${ }^{1,2}$ is currently the best documented example of such events in the Main Asteroid Belt (MAB) thanks to a large number of stratigraphically well-dated, L-chondritic, fossil meteorites $^{3}$. Geochemical analysis has linked the $7.5-\mathrm{km}$ wide Lockne crater, central Sweden, to this family of meteorites ${ }^{4,5}$, which supports the previous notion that also the crater production rate was significantly increased during some millions of years after the MAB event ${ }^{3}$. The recent discovery of the nearby, $0.7-\mathrm{km}$ diameter, contemporaneous Målingen crater $^{6}$ suggests it to form a doublet impact structure together with the larger Lockne crater, and as we will show here, most likely by a binary, 'rubble pile"7 asteroid. Despite observational evidence that about 16\% of the Near Earth Asteroids (NEAs) are binary ${ }^{8}$, only a handful of the approximately 188 known craters on Earth have been suggested as potential doublets, i.e. Clearwater East \& West (Canada), Kamensk \& Gusev (Russia), Ries \& Steinheim (Germany), Suvasvesi North \& South (Finland), and Serra da Cangalha \& Riachão (Brazil $)^{9,10}$, of which most are still disputed ${ }^{11}$. The continuous sedimentation in the marine target environment at Lockne (diameter of apparent crater, $\left.D_{A}=7.5 \mathrm{~km}\right)$ and Målingen $\left(D_{A}=0.7 \mathrm{~km}\right)$ has allowed both impact craters to be biostratigraphically dated and correlated with great precision ${ }^{6}$. The two craters are situated approximately $16 \mathrm{~km}$ center-to-center distance from each other (Fig. 1). Whereas the Målingen crater until now has been known only as an enigmatic, circular feature with lithologies of similar type as at Lockne $^{6}$, the Lockne crater has been extensively studied for the past few decades e.g. refs. 12, 13. At the time of the impact, the Lockne-Målingen area was located on the southern hemisphere in an epicontinental sea that covered most of current Baltoscandia (Fig. 2). The target water depth was approximately $500 \mathrm{~m}$, i.e. about equal to the estimated 600-m diameter Lockne impactor, when modeled as a massive object ${ }^{13}$. The Målingen impactor would have been about $150 \mathrm{~m}$ in diameter ${ }^{14}$.

Recent studies suggest that Målingen, just as Lockne, retains much of its original shape, sedimentary infill, and ejecta deposits ${ }^{6}$. Shock metamorphic evidence has confirmed its impact origin ${ }^{6,15}$. The good preservation of the two adjacent craters is due in large part to the fortunate combination of the marine target environment, wherein continued sedimentation covered and protected the newly formed craters, and that they subsequently became entombed by overthrust nappes of the Caledonian orogeny ${ }^{12}$. Subaerial and glacial erosion have since then reexposed the craters, but with surprisingly small effects on their original morphologies and the preservation of the impactites. From the ejecta distribution, it is possible to deduce that the impact trajectory was from today's east towards west, and with an impact angle of about $45^{\circ}{ }^{13}$.

The relatively rapid post-impact sedimentation in the craters allows high precision in chronobiostratigraphic dating ${ }^{6}$. The impact event occurred during the lower part of the, in Baltoscandia synchronous, chitinozoan Lagenochitina Dalbyensis Zone. Considering the relatively short time span of 0.1-1 million years for the $L$. 


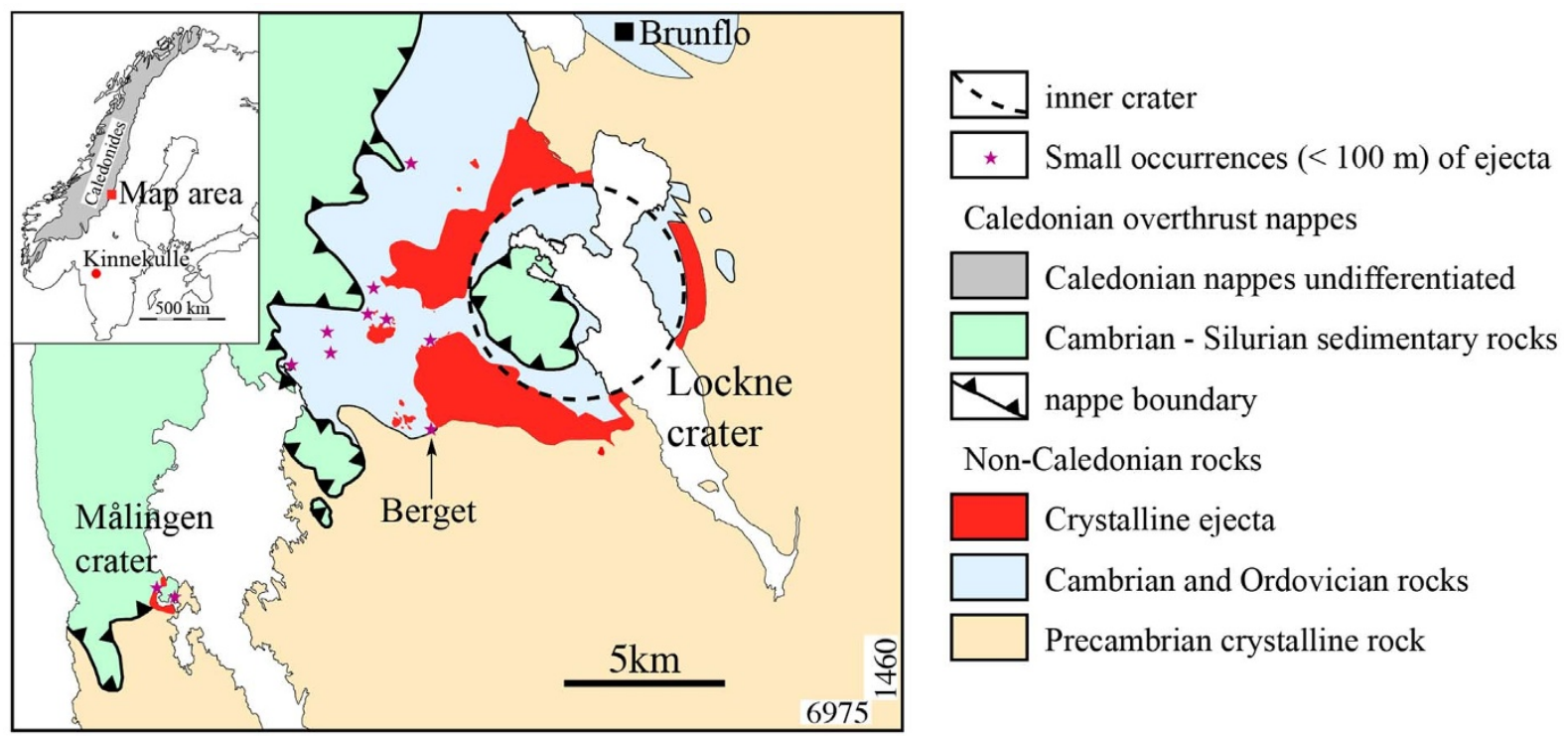

Figure 1 The location of places mentioned in the text, the Lockne-Målingen doublet impact structure, and the distribution of crystalline ejecta from the inner, nested, basement craters. The map is created in Adobe Illustrator 10 based on several decades of mapping in the area led by the authors J. O., E. S., and our late colleague Professor Maurits Lindström. Some of the mapping results have been published ${ }^{6,12}$, but are subject to constant revision.

dalbyensis Zone, the age of the craters can be estimated to $458 \pm$ $0.5 \mathrm{Ma}^{6}$. Schmieder et al. ${ }^{11}$ state that only a synchronicity of two neighboring impact events within $\sim \pm 0.5 \%$ hardens the evidence for double impact, a requirement well fulfilled by LockneMålingen (i.e., \pm 0.5 m.y. equals an error of $<0.1 \%$ ). Moreover, our inspection of continuous drill cores penetrating both craters have not revealed any sign of reworking or a distal ejecta layer in the postimpact sequences of either crater, which would be expected in the case of two separate impact events.

In the Thorsberg quarry at Kinnekulle in southern Sweden (Fig. 1), the discovery of $>90$ fossil L-chondritic meteorites in a Middle Ordovician limestone section ${ }^{16}$, which were deposited over a period of $\sim 2$ m.y. ${ }^{3,17}$, support the theory that the meteorite flux to Earth, and likely also the cratering rate, was enhanced by one to two orders of magnitude for at least a few million years as a consequence of the large breakup event in the MAB $\sim 470 \mathrm{Ma}^{3,18}$. The increased influx was further corroborated by the analysis of the approximately 5 m.y. younger meteorite from Brunflo ${ }^{19}$, near the Lockne crater (Fig. 1), and additional findings of equally high concentrations of L-chondritic chromite micrometeorites in both Chinese and Russian coeval limestones ${ }^{20,21}$. In figure 2, we have plotted confirmed Middle- to early Late Ordovician impact craters in Europe and North America as well as a timeline with known craters and meteorite falls from the first few tens of millions of years following the $\sim 470 \mathrm{Ma}$ asteroid breakup to illustrate the position of the Lockne-Målingen impact in the succession of events.

On the Baltoscandian shield, five confirmed (Lockne-Målingen, Tvären, Granby, Kärdla) and one suspected (Hummeln) impact craters of relevant ages have been identified so far (Fig. 2; Supplementary Table 1). Of these craters, only Lockne has been studied in sufficient detail with respect to its meteoritic component to unequivocally be linked to the L-chondrite parent body ${ }^{4,5}$. However, preliminary results from our ongoing search for chromite in the Målingen resurge deposits indicate an impactor of similar composition as at Lockne. A more comprehensive study dealing with the identification of the impactor is planned. Thus, the lithology of the Lockne-, and possibly also the Målingen-, impactor is known from chemistry. In addition, as we will show here, its physical properties can be inferred by the circumstance of a doublet crater and its geomorphology.

The probability that Lockne and Målingen occurred together by chance, rather than having been paired in space can best be calculated supposing that Lockne (i.e., the larger, less frequent size of the two) formed first during the c. 1 million year interval allowed by the $\pm 0.5 \mathrm{~m}$. y. uncertainty in their crater ages. The maximum distance between two craters to be considered a doublet is $120 \mathrm{D}_{\mathrm{p}}$, where $\mathrm{D}_{\mathrm{p}}$ denotes the diameter of the principal object. It is controlled by the maximum limit of stability of an asteroid satellite ${ }^{22,23}$. For the Lockne impactor $\left(D_{p}=600 \mathrm{~m}\right)$ this gives a $144 \mathrm{~km}$ in diameter circular area, which represents about $3.2 \times 10^{-5}$ of the Earth's surface. The probability that a crater of Målingen's diameter forms somewhere on Earth is today about $9 \times 10^{-5}$ per year ${ }^{24}$, but here we adjust this with the maximum estimate of a two orders of magnitude higher cratering rate for the time period of interest ${ }^{3,18}$. The probability of a chance occurrence within $144 \mathrm{~km}$ is about 0.29 when assuming the highest cratering rate. If we restrict the range to the observed $16 \mathrm{~km}$ between the two craters, the probability of a chance occurrence falls to $1.4 \times$ $10^{-2}$. Even if assuming the highest suggested cratering rate of two orders of magnitude higher than today's impact flux the cratering rate must still have to be raised by a factor between 3.4 (for the $144 \mathrm{~km}$ range) to 71 (for the observed $16 \mathrm{~km}$ separation) to make the association between Lockne and Målingen a chance event, which is very unlikely.

Thus, with an unequivocal doublet impact at Lockne-Målingen we can assess the physical properties of the culprit binary projectile. The fragmentation of a parent asteroid tends to lead to gravitational reaccumulation of dust and coarser debris to form families of 'rubble pile' asteroids ${ }^{7}$. Simulation has shown that the formation of satellites around parent bodies is a natural and frequent outcome of this type of collisional events $\mathrm{s}^{7,22,25}$. Other potential processes for binary formation, e.g. capture, are considered of less importance in the LockneMålingen case due to low probability and insufficient separation between the bodies ${ }^{8}$.

The nearly horizontally configured target sequence at Lockne and Målingen comprised $\sim 500 \mathrm{~m}$ of seawater, $\sim 50 \mathrm{~m}$ of lithified, bedded 'orthoceratite limestone,' and $\sim 30 \mathrm{~m}$ of dark, organic-rich mud (today 'alum shale'), resting on a peneplained Proterozoic crystalline basement ${ }^{6,12,13}$. Numerical simulations of the marine Lockne impact event show the development of a 'soup plate' -shaped concentric transient cavity that is also reflected in the apparent morphology of the crater, and that only large (tens of meters) ejecta blocks from the inner, deeper, 'nested' crater in the basement was able to penetrate the water cavity wall and impact the sea up to $6 \mathrm{~km}$ beyond 

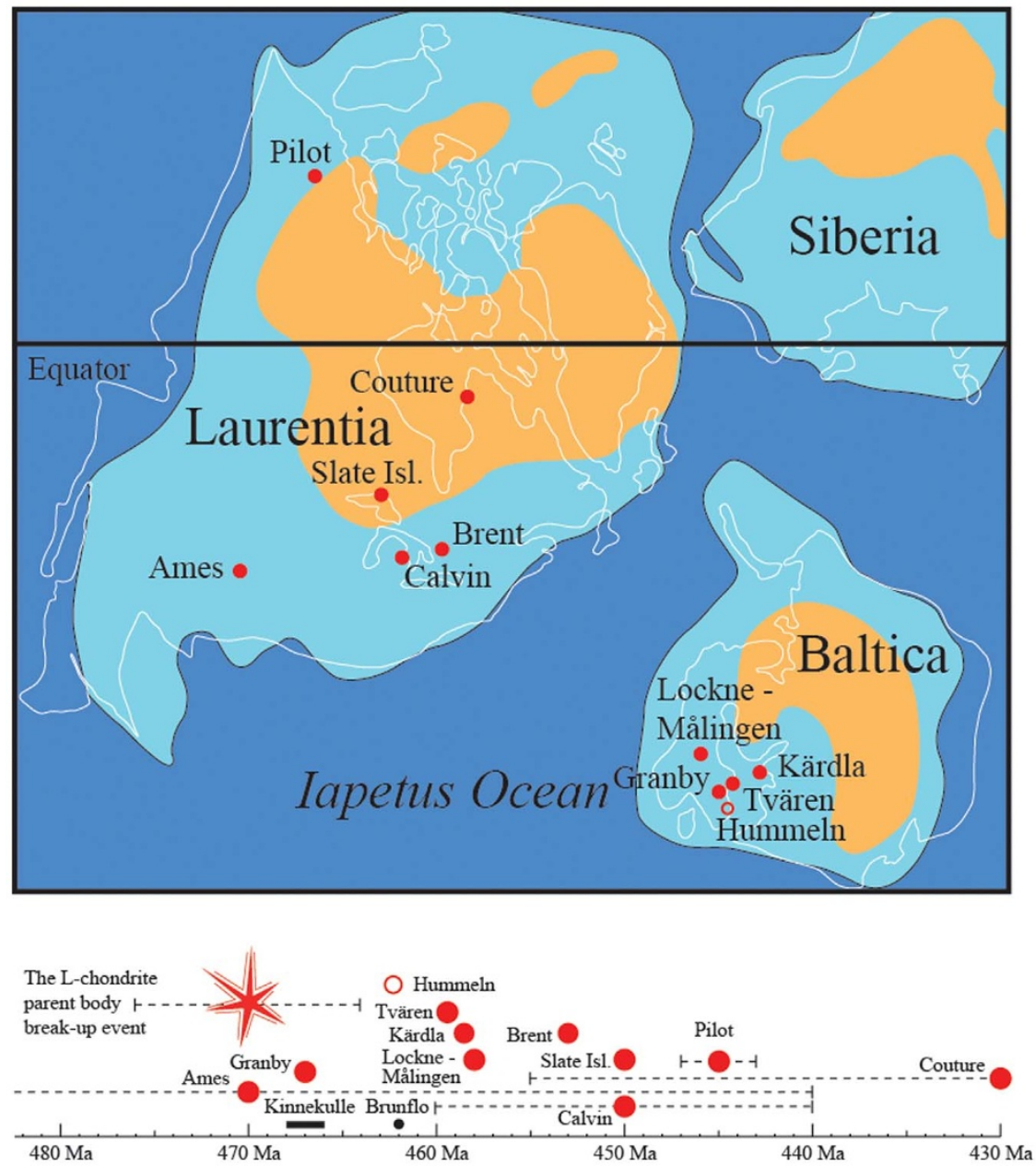

Figure $2 \mid$ Paleogeography of Baltica and neighboring cratons at the time of the increased cosmic bombardment following the $\sim 470$ Ma asteroid breakup event, and timeline for the related meteorite falls (black dot and line) as well as known craters (red dots). Light blue color represents areas of shallow epicontinental seas, and dark blue areas of deep ocean. This distribution may, however, have varied somewhat due to periodical transgressions and regressions of the sea. The map is created in Adobe Illustrator 10. Paleogeographic map modified from PALEOMAP Project ${ }^{30}$. For details on the craters and meteorite falls see Supplementary Table 1.

the center of the target (i.e., $>2.5 \mathrm{~km}$ outside the nested crater rim) ${ }^{13}$. The extent of the outer crater outside the nested crater rim is in the simulations at the most $\sim 2 \mathrm{~km}$ on the down-range side and even less on the up-range side $^{13}$. However, the simulations assumed a monolithic impactor. We here argue that the observed geology of the Lockne crater is more consistent with the impact of a fragmented projectile. For instance, up to $100 \times 100 \mathrm{~m}$ wide bodies of ballistic basement crater ejecta in the form of a crystalline breccia occur at three times the distance of the modelled extent of the outer crater in the seawater and sediments on the western, down-range side (Fig. 1). These ejecta lie in stratigraphic positions indicating several tens of meters penetration into the sedimentary succession. It seems unlikely that the crystalline ejecta could have passed the water cavity wall and the layer of seawater intact and with enough force for this penetration into the seafloor (Fig. 3). Thus, the outer crater of Lockne must have been wider than indicated by the numerical simulations using a massive impactor. In addition, geophysical modeling (magnetic and gravity) has indicated a relatively shallow nested crater in the basement with a poorly developed central uplift despite a diameter well above the simple- to complex crater transition ${ }^{26,27}$. Likewise, core drilling and geological mapping of the Målingen crater have revealed a similar shallow and wide outer crater surrounding a relatively shallow nested, basement crater compared with the expected depth-to-diameter ratio of a simple crater in crystalline rock ${ }^{6}$. We believe that the reasons for these unusual morphologies of Lockne and Målingen are to be found in the properties of the projectile. During the passage of the atmosphere a fragmented or 'rubble pile' asteroid in the size range of the LockneMålingen projectiles will be subject to aerodynamic breakup. Numerical simulation has shown that aerodynamic disruption is expected for monolithic, rocky meteors of less than $200 \mathrm{~m}$ in diameter, and that they then develop into a broad, flat projectile with a crosssection that may exceed that of the parent body by an order of magnitude ${ }^{28}$. A similarly-sized weaker body such as a comet would develop into a debris jet ${ }^{28}$. Obliquity of impact is intensifying the breakup effect. For already fragmented, or 'rubble pile', asteroids it can be expected that the same occurs also for a significantly larger projectile diameter than for a monolithic. Likewise, a low-density impactor is known to produce a relatively smaller and shallower crater than a dense projectile with the same kinetic energy ${ }^{29}$. However, the fragmentation may be of less importance for the cratering process if the effective diameter of the disrupted impactor, or debris jet, is smaller than the diameter of the expected transient crater from an equal mass nondisrupted impactor ${ }^{28}$. The numerical simulation of the Lockne impact assuming a monolithic $600-\mathrm{m}$ in diameter projectile gave a transient crater diameter of $5 \mathrm{~km}^{13}$. Thus, with an order of magnitude wider diameter for an aerodynamically disrupted projectile (i.e. $6 \mathrm{~km}$ ) it would exceed the transient crater width, and affect the cratering process leading to the observed geomorphology of the Lockne crater. 


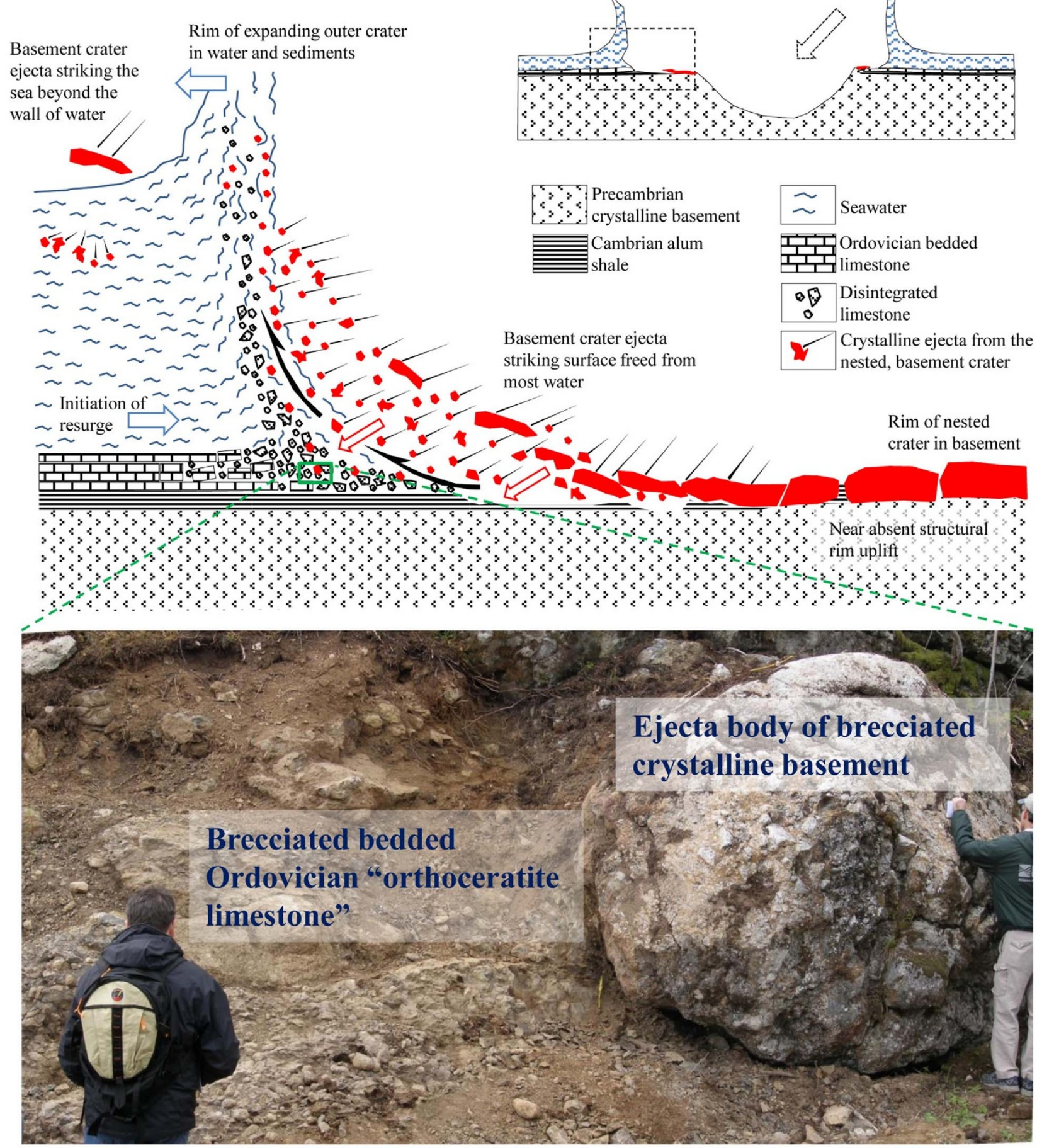

Figure $3 \mid$ The development of the unusually wide brim (i.e., outer crater) in the water column and sedimentary strata surrounding the nested, basement crater of the Lockne impact structure (inset figure indicates the down-range location). Preserved bodies of crystalline ejecta (photo of locality "Berget", Fig. 1) have penetrated tens of meters down into the succession of consolidated limestones and are thus thought to have landed directly on exposed sedimentary strata without first passing the water cavity wall and the hundreds of meters thick water column.

The here presented unique Lockne-Målingen doublet offers a likewise unique opportunity to reconstruct the properties of an impactor (i.e., L-chondritic, fragmented or even 'rubble-pile', binary asteroid) and to provide detailed ground truth in deciphering the consequences such a projectile has on the cratering process, ejecta distribution, and the final crater shape. This is to great aid in the interpretation of remote sensing data from doublets on other planetary bodies such as the moon and Mars. In addition, the precise dating of the Lockne-Målingen impact in relation to the MAB breakup event provides a hands-on reference for studies of the formation of binaries from asteroid breakup events.

1. Keil, K., Haack, H. \& Scott, E. R. D. Catastropic fragmentation of asteroids Evidence from meteorites. Planet. Space Sci. 42, 1109-1122 (1994).

2. Korochantseva, E. V. et al. L-chondrite asteroid breakup tied to Ordovician meteorite shower by multiple isochron ${ }^{40} \mathrm{Ar}-{ }^{39} \mathrm{Ar}$ dating. Meteorit. Planet. Sci. 42, $113-130$ (2007). 
3. Schmitz, B., Tassinari, M. \& Peucker-Ehrenbrink, B. A rain of ordinary chondrites in the early Ordovician. Earth Planet. Sci. Lett. 194, 1-15 (2001).

4. Alwmark, C. \& Schmitz, B. Extraterrestrial chromite in the resurge deposits of the early Late Ordovician Lockne crater, central Sweden. Earth Planet. Sci. Lett. 253, 291-303 (2007).

5. Schmitz, B. et al. Determining the impactor of the Ordovician Lockne crater: oxygen and neon isotopes in chromite versus sedimentary PGE signatures. Earth Planet. Sci. Lett. 306, 149-155 (2011).

6. Ormö, J. et al. The geology of the Målingen structure: A probable doublet to the Lockne marine-target impact crater, central Sweden. Meteorit. Planet. Sci. 49, 313-327 (2014).

7. Michel, P., Benz, W., Tanga, P. \& Richardson, D. C. Collisions and Gravitational Reaccumulation: Forming Asteroid Families and Satellites. Science 294, 1696-1700 (2001)

8. Margot, J. L. et al. Binary Asteroids in the Near-Earth Object Population. Science 296, 1445-1448 (2002).

9. Melosh, H. J. \& Stansberry, J. A. Doublet craters and the tidal disruption of binary asteroids. Icarus 94, 171-179 (1991).

10. Miljković, K., Collins, G. S., Mannick, S. \& Bland, P. A. Morphology and population of binary asteroid impact craters. Earth Planet. Sci. Lett. 363, 121-132 (2013).

11. Schmieder, M., Trieloff, M., Schwarz, W. H., Buchner, E. \& Jourdan, F. Supportive comment on: "Morphology and population of binary asteroid impact 3 craters", by K. Miljković, G. S. Collins, S. Mannick and P. A. Bland 4 [Earth Planet. Sci. Lett. 363 (2013) 121-132] - An updated assessment. Earth Planet. Sci. Lett. (In press).

12. Lindström, M., Ormö, J., Sturkell, E. \& v. Dalwigk, I. In Impact Studies: Impact Tectonics (eds Koeberl, C. \& Henkel, H.) 357-388 (Springer, Berlin-Heidelberg, 2005).

13. Lindström, M., Shuvalov, V. \& Ivanov, B. Lockne crater as a result of marine-target oblique impact. Planet. Space Sci. 53, 803-815 (2005).

14. Davison, T. \& Collins, S. The effect of the oceans on the terrestrial crater sizefrequency distribution: insight from numerical modeling. Meteorit. Planet. Sci. 42, 1915-1927 (2007).

15. Alwmark, C., Holm, S., Ormö, J. \& Sturkell, E. Shocked quartz from the Målingen structure, Sweden - evidence for a twin crater to the Ordovician Lockne marine target impact structure. Meteorit. Planet. Sci. (In press).

16. Schmitz, B., Peucker-Ehrenbrink, B., Lindström, M. \& Tassinari, M. Accretion rates of meteorites and cosmic dust in the early Ordovician. Science 278, 88-90 (1997).

17. Alwmark, C., Schmitz, B., Meier, M. M. M., Baur, H. \& Wieler, R. A global rain of micrometeorites following breakup of the L-chondrite parent body-evidence from solar wind-implanted $\mathrm{Ne}$ in fossil extraterrestrial chromite grains from China. Meteorit. Planet. Sci. 47, 1297-1304 (2012).

18. Zappala, V., Cellino, A., Gladman, B. J., Manley, S. \& Migliorini, F. Asteroid showers on Earth after family break-up events. Icarus 134, 176-179 (1998).

19. Alwmark, C. \& Schmitz, B. The origin of the Brunflo fossil meteorite and extraterrestrial chromite in mid-Ordovician limestone from the Gärde quarry (Jämtland, central Sweden). Meteorit. Planet. Sci. 44, 95-106 (2009).

20. Cronholm, A. \& Schmitz, B. Extraterrestrial chromite distribution across the midOrdovician Puxi River section, central China: Evidence for a global major spike in flux of L-chondritic matter. Icarus 208, 36-48 (2010).

21. Lindskog, A., Schmitz, B., Cronholm, A. \& Dronov, A. A Russian record of Middle Ordovician meteorite shower: extraterrestrial chromite at Lynna River, St. Petersburg region. Meteorit. Planet. Sci. 47, 1274-1290 (2012).

22. Cuk, M. Formation and destruction of small binary asteroids. Astrophys. J. 659, L57-L60 (2007).
23. Bottke, W. F. \& Melosh, H. J. The formation of binary asteroids and doublet craters. Icarus 124, 372-391 (1996).

24. Bland, P. A. \& Artemieva, N. A. The rate of small impacts on Earth. Meteorit Planet. Sci. 41, 607-631 (2006).

25. Walsh, K. J., Richardson, D. C. \& Michel, P. Rotational breakup as the origin of small binary asteroids. Nature 454, 188-191 (2008).

26. Sturkell, E. F. F., Ekelund, A. \& Törnberg, R. Gravity modelling of Lockne, a marine impact structure in Jämtland, central Sweden. Tectonophysics 296, 421-435 (1998)

27. Sturkell, E. F. F. \& Ormö, J. Magnetometry of the marine, Ordovician Lockne impact structure, Jämtland, Sweden. J. Appl. Geophys. 38, 195-207 (1998).

28. Shuvalov, V. V. In Impacts in Precambrian Shields (eds Plado, J. \& Pesonen, L. J.) 323-336 (Springer, Berlin-Heidelberg, 2002).

29. O'Keefe, J. D. \& Ahrens, T. J. Cometary and meteorite swarm impact on planetary surfaces. J. Geophys. Res. 87, doi: 10.1029/0JGREA0000870000B8006668000001. issn, 0148-0227. (1982).

30. Scotese, C. R. PALEOMAP Project (http://www.scotese.com) 2002 (Accessed 01/ 03/2014).

\section{Acknowledgments}

The work by J. Ormö is supported by grants AYA2008-03467/ESP and AYA2011-24780/ ESP from the Spanish Ministry of Economy and Competitiveness, and project 90449201 "Concentric Impact Structures in the Palaeozoic (CISP)" from the Swedish Research Council (Vetenskapsrådet). The work by C. Alwmark is supported by a grant from the Swedish Research Council. The authors are grateful to David T. King, Jr., Auburn University for valuable comments on an early version of the paper.

\section{Author contributions}

The authors J.O., E.S. and C.A. contributed equally to the fieldwork, data analysis, preparation of figures, and writing of the paper. The author J.M. contributed with the calculation of the probability of Lockne-Målingen as doublet impact. All authors reviewed the manuscript.

\section{Additional information}

Supplementary information accompanies this paper at http://www.nature.com/ scientificreports

Competing financial interests: I declare that the authors have no competing interests as defined by Nature Publishing Group, or other interests that might be perceived to influence the results and/or discussion reported in this paper.

How to cite this article: Ormö, J., Sturkell, E., Alwmark, C. \& Melosh, J. First known Terrestrial Impact of a Binary Asteroid from a Main Belt Breakup Event. Sci. Rep. 4, 6724; DOI:10.1038/srep06724 (2014).

This work is licensed under a Creative Commons Attribution-NonCommercialNoDerivs 4.0 International License. The images or other third party material in this article are included in the article's Creative Commons license, unless indicated otherwise in the credit line; if the material is not included under the Creative Commons license, users will need to obtain permission from the license holder in order to reproduce the material. To view a copy of this license, visit http:// creativecommons.org/licenses/by-nc-nd/4.0/ 